\title{
Ca-alginate spheres behavior in presence of some solvents and water-solvent mixtures
}

\author{
Luis G. Torres, Angelica Velasquez, Marco A. Brito-Arias
}

Unidad Profesional Interdisciplinaria de Biotecnología. Instituto Politecnico Nacional. Av. Acueducto s/n. Colonia Barrio la Laguna Ticoman; delegacion Gustavo A. Madero 07340 D. F., Mexico.

Email: LTorresB@ipn.mx

Received 25 June 2010; revised 5 July 2010; accepted 12 July 2011.

\begin{abstract}
Immobilization systems more frequently used are calcium alginate spheres. These biocatalysts have many potential applications in the immobilization of enzymes, prokaryotic cells, vegetal and animal cells, algae, organelles and mixtures of these living components. Other applications of immobilized cells imply the use of non aqueous systems. Some bioconversions are carried out in the presence of solvents such as hexane acetone or acetonitrile, or mixtures water-solvents. The aim of this work was to investigate the behaviour of Ca-alginate spheres when put in contact with different solvents (water, diesel, ethanol, methanol, acetone, n-hexane, isopropyl alcohol, THF, acetonitrile, and toluene), or solvent-water mixtures (i.e., ethanol-water), regarding the resistance of the alginate spheres after days of contact. Calcium alginate particles suffered different damages, depending on the solvent they were put in contact. Water did not damaged the Ca-alginate structure with or without Ca present. On the other hand different solvents lost a proportion of volume, i.e., n-hexane (16\%), methanol $(19 \%)$, ethanol (19.5\%), toluene (22\%), diesel (34\%), acetone (765), isopropyl alcohol $(80 \%)$, THF and acetonitrile (total loss, total destruction). Nor the dielectric constant nor the polarity indexes were capable of explaining the difference on the volume loss or total sphere destruction, except for water-ethanol mixtures.
\end{abstract}

Keywords: Dielectric Constant; Ca-Alginate; Immobilization, Solvents; Spheres; Polarity Index

\section{INTRODUCTION}

Nowadays, there is an increasing interest in producing high amounts of ethanol as an alternative fuel to fossil fuels in the whole world. In the USA, the production demand for 2012 is 7.5 billion gallons per year [1].
Ethanol is a valuable alternative to petroleum-based transportation fuels. The traditional ethanol manufacture was using sugar and yeast, though there are many other alternatives such as using wheat, barley, sorghum, beets, cheese whey, potatoes, and many other feedstocks [2]. Over $90 \%$ of the ethanol produced in USA is made of corn. In opposite, in Brazil-the world's largest producer-most ethanol is made from sugar cane. Other sugar sources for ethanol production are cellulosic feedstocks, i.e. agricultural waste, forestry residues and even solid municipal waste [2].

Many microorganisms can convert sugars to ethanol, and they can do it as free cells or into immobilized systems. These systems have proved to enhance production rates based in simple facts as the following: 1) immobilized systems can achieve high cell loads and maintain them for longer periods, 2) immobilization systems have a protector effect over cells, in particular when products or substrates are toxic to cells [3], and 3) these systems are flexible and allow the co-immobilization of different microorganisms or microorganisms and enzymes, or even cofactors.

Immobilization systems more frequently used are calcium alginate spheres [4]. These biocatalysts have many potential applications in the immobilization of enzymes, prokaryotic cells, vegetal and animal cells, algae, organelles and mixtures of these living components. See Chevalier and de la Noue [5] experiments with co-immobilization of algae and bacteria.

Other applications of immobilized cells imply the use of non aqueous systems. Some bioconversions are carried out in the presence of solvents such as hexane acetone or acetonitrile, or water-solvents mixtures.

In recent years, it has been reported the use of immobilized microorganisms in order to modify the content of certain molecules present in crudes and fractions, such as diesel or gasolines. Target molecules are sulphur or nitrogen compounds, with linear, branched, cyclic or even aromatic structures. 
Many other systems have been reported, where Caalginate spheres deals with presence of non aqueous phases. Hedstrom et al. [6] used this kind of gels to immobilize Candida antartica lipase in the esterification of 2-octanol and hexanoic acid in hexane.

To mention other, Hertzberg et al. [7] worked with immobilized lipase to catalyze alkyl butanoate formation, transesterification reactions and hydrolysis of butyl butanoate. For these reactions, the authors assessed the stability of calcium alginate beads in ethanol, acetone, pyridine, 2-butanone, hexane, and iso-hexane. They measured the relative volume change when beads were transferred from $\mathrm{CaCl}_{2}$ to different solvents.

When calcium alginate spheres are putt in contact with different solvents and solvents-water mixtures, different behaviours are depicted. It has been reported that Ca-alginate spheres as any hydrogel are constituted mainly by water (typically 96-99\%), tend to be dehydrated in contact with alcohols, such as ethanol or isopropyl alcohol. Other solvents cause other damages in the Ca-alginate spheres such as shrinking, deformation, dryness, and even destruction.

The aim of this work was to investigate the behaviour of Ca-alginate spheres when put in contact with different solvents (water, diesel, ethanol, methanol, acetone, n-hexane, isopropyl alcohol, THF, acetonitrile, and toluene), or solvent-water mixtures (i.e. ethanolwater), regarding the resistance of the alginate spheres after days of contact.

\section{MATERIALS AND METHODS}

\subsection{Ca-Alginate Spheres Preparation.}

Ca-alginate spheres were prepared in accord to the procedure previously reported by Torres et al. [8]. Na-alginate solutions were dropped in $0.1 \mathrm{M} \mathrm{CaCl}_{2}$ solutions using system in order to control the spheres diameter in about $3 \mathrm{~mm}$. Spheres were prepared using calcium alginate solutions containing $3 \%$ of sodium alginate.

\subsection{Solvents}

Double-distilled water was prepared in our laboratory by ultra filtration. Ethanol, methanol acetonitrile, THF, nhexane, acetone, toluene and isopropylic alcohol were purchased either with J.T. Baker or Aldrich Chemicals. Diesel was a commercial sample, purchased in a Mexico City gas station. Some properties of those solvents such as dielectric constant and polarity index are shown at Table 1.

\subsection{Average Sphere Diameters}

Average diameters were determined measuring 20 spheres with a veneer. Standard deviations were calcu-
Table 1. Some solvent physichochemical properties.

\begin{tabular}{ccc}
\hline \multirow{2}{*}{ Solvent } & $\begin{array}{c}\text { Dielectric constant } \\
\text { DC }\end{array}$ & Polarity Index* \\
\hline Water & 80.0 & 9.0 \\
Ethanol & 24.6 & 5.2 \\
Methanol & 32.7 & 5.1 \\
Acetonitrile & 37.5 & 5.8 \\
THF & 4.0 & 4.0 \\
n-Hexane & 1.9 & 0.0 \\
Acetone & 21 & 5.1 \\
Isopropyl alcohol & 20.3 & 3.9 \\
Toluene & 2.3 & 2.4 \\
\hline
\end{tabular}

*From http: //www.chemical-ecology.net/java/solvents.htm

lated using Excel program (Microsoft).

\subsection{Spheres Behaviour in Presence of Different Solvents and Mixtures}

200 prepared alginate beads were put in a $250 \mathrm{ml} \mathrm{Er}$ lenmeyer flask together with $100 \mathrm{ml}$ the selected solvent or mixture. Flasks were gently shaked in an orbital agitator for 4 days. A sample of 20 spheres was employed to measure initial and final average diameters.

\section{RESULTS AND DISCUSSION}

Table 2 shows the changes suffered by 3\% calcium alginate spheres after 3 days submerged in the different solvents. In the case of water, a $0.1 \mathrm{MCaCl}_{2}$ solution was used to prevent Ca diffusion from the spheres to the water. Initial batches of spheres were $3.13 \mathrm{~mm}$ in diameter.

Ca-alginate spheres were submerged in the solvents and observed after 24, 48, 72 and 96 hours. All experiments were carried out at room temperature (about $20 \pm$ $2^{\circ} \mathrm{C}$ ). Spheres submerged in water (added with $\mathrm{CaCl}_{2}$ ) did not show any change during the four days, as expected. At the end of the process the spheres looked just like at the beginning of the experiment and the average sphere diameter decreased up to $3.047 \pm 0.026 \mathrm{~mm}$, giving a volume loss of about $2.9 \%$, which is negligible.

That was not the case of the spheres submerged in n-hexane, where the particles were adhered to the bottom of the flask from the beginning, they turned yellow and at day four, all spheres seem very soft. After measuring the averaged diameter of 20 particles, the final diameter was of $2.904 \pm 0.177 \mathrm{~mm}$, resulting in a volume loss of $15.9 \%$, which is an important figure.

When immersing the $200 \mathrm{Ca}$-alginate spheres on methanol, no changes were observed during the first 24 hours, but at the second day, some turbidity appeared in the flask. At third day turbidity was a little higher but no changes were observed at day 4 . Final average diameter 
Table 2. Changes in the Ca-alginate spheres when submerged in different solvents.

\begin{tabular}{ccccccc}
\hline & & \multicolumn{2}{c}{ Elapsed time (days) } & & Final diameter \\
Ave \pm std dev & Volume \\
loss (\%)
\end{tabular}

was $2.80 \pm 0.032 \mathrm{~mm}$, with a volume loss of $18.8 \%$. The behaviour of Ca-alginate spheres in ethanol was very similar to that observed in methanol, as expected. In this case, the final sphere diameter was in average $2.863 \pm$ $0.072 \mathrm{~mm}$, and the volume loss was of $19.5 \mathrm{~mm}$.

When Ca-alginate particles were submerged in toluene, it was observed that particles were adhered to the bottom from the first day and at the end of the process, spheres were very brilliant, with an average final diameter of $2.837 \pm 0.212 \mathrm{~mm}$ and a volume loss of $21.6 \%$.

In the case of diesel, it was observed that spheres tend to agglomerate, and at the end of the process the particles were very brilliant and the volume loss was of $34 \%$.

When Ca-alginate spheres were submerged for 4 days in acetone, the media turned very yellow and the final average diameter was of $2.003 \pm 0.54 \mathrm{~mm}$, giving a volume loss of $75.6 \%$. When spheres were put in contact with iso-propylic alcohol, an important diameter diminution was observed at the second day, and at the end of the process very stiff, small particles were produced. Final average diameter was of $1.788 \pm 0.158 \mathrm{~mm}$ and the volume loss was of $80.4 \%$.

The last two experiments were similar in results. When immersing the Ca-alginate spheres on acetonitrile and THF, destruction of the spheres was observed, turbidity appeared from the beginning of the process and it was impossible to determine for both cases the final spheres average diameter. It was considered that the sphere were unrecovered.

It is well known that Ca-alginate spheres are produced by the interaction of alginic acid, which is a linear polysaccharide and the divalent calcium, forming a structure known as the egg-box model. The destruction of the Ca-alginate gel should be promoted by the Ca loss, or either by the solubilisation of water in the added solvent.
A way to analyze the effect of the characteristics of the added solvent is the measure of the polarity index and the dielectric constant of solvents.

The first is the relative measure of the degree of interaction of the solvent with various polar test solutes. In that way, pentane and 1,1,2-trichlorotrifluoroethane have a polarity index of 0 (no interaction). Cyclopentane, heptane, hexane, iso-octane and petroleum ether have very low polarity indexes (0.1).

On the other hand, dimethyl acetamide (6.5), n-methylpyrrolidone (6.7) and dimethyl sulfoxide (7.2) have high polarity indexes. In the case of water, a value of 9-10 has been reported. In the case of diesel, it is not possible to give a figure for dielectric constant. Since this is a mixture of many compounds, and diesel has a huge variability depending of the source (crude) and process employed to produce it.

The dielectric constant values are referred to the measure of extent to which concentrates electrostatic lines of flux. It is the ratio of the amount of stored electrical energy when a voltage is applied, relative to the permittivity of a vacuum. The correct name for this parameter should be relative static permittivity.

With these facts in mind, the loss of volume (\%) measured in every experiments were plotted as a function of the polarity index in Figure 1. As noted, four of the points are around $15-20 \%$ volume loss, for polarity indexes between 0 and 5.2. For one of the points (that corresponding to water added with calcium), volume loss is negligible (2.9\%). There are two points with high volume losses (acetone and isopropyl alcohol, with polarity indexes between 5.1 and 3. That means that polarity index do not explain why some Ca-alginate spheres shrink in some solvents more than in others.

In a new intent to explain the Ca-alginate volume loss 


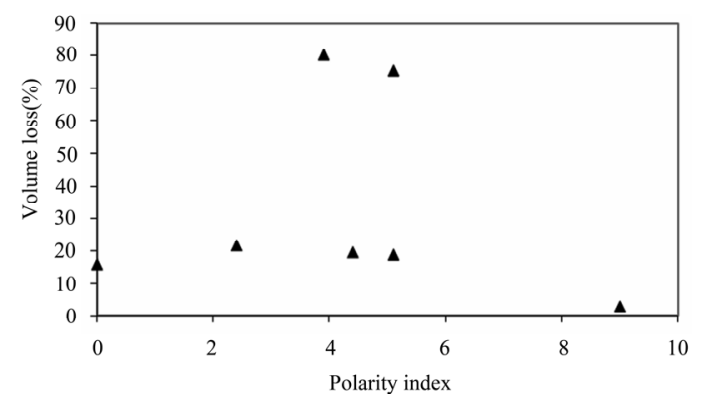

Figure 1. Volume loss vs polarity index for different solvents.

in the different solvents, Figure 2 shows the plot of the dielectric constant value for the different solvents, and the corresponding volume loss (\%). Again, most of the points of dielectric constant between 0 and 35, corresponded to volume loss of around $20 \%$.

A new set of experiments were carried out using water, ethanol and water-ethanol mixtures. The results of the experiments after 4 days are those shown in Table 3 . The polarity indexes and dielectric constants for the water-ethanol mixtures are also included. It is interesting to note that volume loss for Ca-alginate particles was of only $2.7 \%$ in the case of water (no $\mathrm{CaCl}_{2}$ was added), while for pure ethanol the volume loss was of 38.25.

The rest of the volume losses seem to be proportional to the water-ethanol mixture. If the values of volume loss for the particles are plotted against the polarity indexes PI for the given water-ethanol mixtures, a straight line represents the behaviour of the experimental line, with a $\mathrm{R}^{2}$ value of 0.96 (see Figure 3 ).

The equation is:

$$
\text { Volume loss }(\%)=5.73+7.39(P I)
$$

When the volume loss was plotted against the dielectric constant DC a straight line was obtained too (figure not shown), but the form of the resulting equation is:

$$
\text { Volume loss }(\%)=52.69-0.595(D C)
$$

With $\mathrm{R}^{2}=0.976$.

Solvents with a relative static permittivity greater than

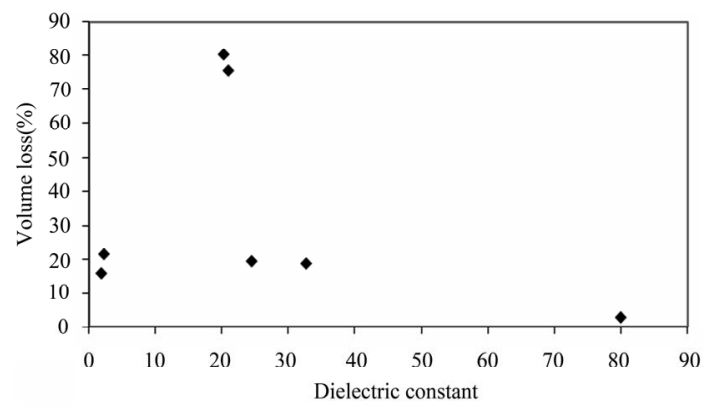

Figure 2. Volume loss vs dielectric constants for different solvents.

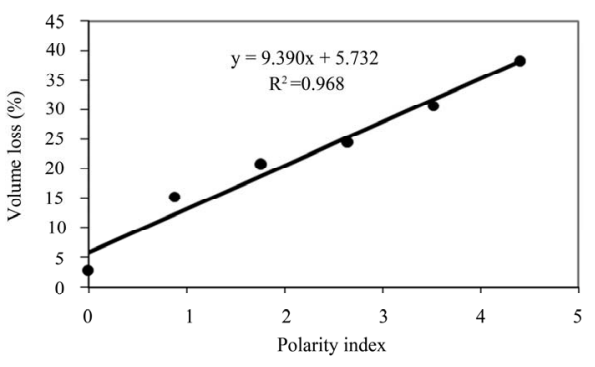

Figure 3. Volume loss vs polarity index for water-ethanol mixtures.

Table 3. Changes in the Ca-alginate spheres when submerged in water-ethanol mixtures.

\begin{tabular}{cccc}
\hline $\begin{array}{c}\text { Water/ethanol } \\
\text { mix }\end{array}$ & $\begin{array}{c}\text { Volume } \\
\text { loss (\%) }\end{array}$ & $\begin{array}{c}\text { Dielectric } \\
\text { constant }\end{array}$ & Polarity index \\
\hline $100 / 0$ & 2.7 & 80 & 0 \\
$80 / 20$ & 15.2 & 67.3 & 0.88 \\
$60 / 40$ & 20.78 & 56.6 & 1.76 \\
$40 / 60$ & 24.4 & 45.9 & 2.64 \\
$20 / 80$ & 30.62 & 35.2 & 3.52 \\
$0 / 100$ & 38.25 & 24.6 & 4.4 \\
\hline
\end{tabular}

From [9].

15 can be further divided into protic and aprotic. Protic solvents solvate anions (negatively charged solutes) strongly via hydrogen bonding. Water is a protic solvent. Aprotic solvents such as acetone or dichloromethane tend to have large dipole moments (separation of partial positive and partial negative charges within the same molecule) and solvate positively charged species via their negative dipole. Using this new division it is possible to analyze briefly the situation again. Acetone, acetonitrile and THF are aprotic solvents, while water and alcohols are non polar ones.

\section{CONCLUSIONS}

Calcium alginate particles suffered different damages, depending on the solvent they were put in contact. Water did not damaged the Ca-alginate structure with or without Ca present. On the other hand different solvents lost a proportion of volume, i.e., n-hexane (16\%), methanol (19\%), ethanol (19.5\%), toluene (22\%), diesel (34\%), acetone (765), isopropyl alcohol (80\%), THF and acetonitrile (total loss, total destruction). Nor the dielectric constant nor the polarity indexes were capable of explaining the difference on the volume loss or total sphere destruction, except for the ethanol-water mixtures.

When putting in contact the Ca-alginate spheres with water, ethanol and water ethanol mixtures, different volume loss (\%) were observed. In this case, both dielectric constants for mixtures and polarity indexes for mixtures, explained the volume loss. Two very simple equations expressing the volume loss as a function of dielectric constant or polarity indexes were developed, 
which result very interesting in predicting the volume loss by s for a given water-ethanol mixture. This is particular important for the case of ethanol production by immobilized cells.

\section{REFERENCES}

[1] Mulson, S. (2007) Ethanol production booming on demand. Washington Post, January 23, 2007.

[2] Morris, M. and Hill, A. (2007) Ethanol opportunities and questions. http://www.attra.ncat.org

[3] Kewellow, H., Heipieper, H.-J. and Rehm, H.-J. (1989) Protection of bacteria against toxicity of phenol by immobilization in calcium alginate, Applied Microbiology and Biotechnology, 31, 283-389.

[4] Smisrod, O. and Skajak-Braek, G. (1990) Alginate as immobilization matrix for cells, Trends in Biotechnology, 8, 71-78. doi:10.1016/0167-7799(90)90139-O

[5] Chevalier, P. and de la Noue, J. (1998) Behavior of algae and bacteria co-immobilized in carrageninana, in a fluidized bed, Enzyme and Microbial Technology, 10, 924.

[6] Hedstrom, G., Backlund, S., Erickson, F. and Karlsson, S. (1998) Lipase-catalyzed stereoselective esterifications using gelatine-based hydrogels, Colloids and Surfaces. B, Biointerfaces, 10, 379-384. doi:10.1016/S0927-7765(98)00015-0

[7] Hertzberg, S., Kvittingen, L., Anthonsen, T. and SkjakBraek, G. (1992) Alginate as immobilization matrix and stabilizing agent in a two-pase liquid system: Application in lipase-catalysed reactions, Enzyme and Microbial Technology, 14, 42-47. doi:10.1016/0141-0229(92)90024-I

[8] Torres, L.G, Sanchez-de-la-Vega, A., Beltran, N.A. and Jimenez, B.E. (1998) Production and characterization of a Ca-alginate biocatalyst for removal of phenol and chlorophenols from wastewaters, Process Biochemistry, 33, 625-634. doi:10.1016/S0032-9592(98)00026-0

[9] Farji, M., Farajtabar, A. and Oharib, F. (2009) Determination of water-ethanol mixtures autotpotolysis constants and solvent effect. Journal of Applied Chemistry Research, 9, 7-12. 